\title{
Development of a clockwork light source to enable cervical inspection by village health workers Fidelma O'Mahony*1, Bob Bailey ${ }^{2}$, Chris Koller ${ }^{1}$, Collette Sheridan ${ }^{2}$, Richard Steventon ${ }^{2}$, Kalyan K Dhar ${ }^{1}$ and Richard B Johanson ${ }^{1}$
}

Address: ${ }^{1}$ North Staffordshire Hospital, Stoke on Trent, Staffordshire, ST4 6QG, UK and ${ }^{2}$ Royal Shrewsbury Hospital, Shrewsbury, Shropshire, SY3 $8 \mathrm{XQ}, \mathrm{UK}$

Email: Fidelma O'Mahony* - fidelma@meole2.freeserve.co.uk; Bob Bailey - rds@rshmes.demon.co.uk;

Chris Koller -Chris.Koller@nstaffsh.wmids.nhs.uk; Collette Sheridan - cms@mcmedia.com.au; Richard Steventon - rds@rshmes.demon.co.uk; Kalyan K Dhar - KDhar@compuserve.com; Richard B Johanson - richard@kogs.freeserve.co.uk

* Corresponding author

Published: 12 December 2002

BMC Women's Health 2002, 2:12
Received: 17 May 2002

Accepted: 12 December 2002

This article is available from: http://www.biomedcentral.com/1472-6874/2/12

(C) 2002 O'Mahony et al; licensee BioMed Central Ltd. This is an Open Access article: verbatim copying and redistribution of this article are permitted in all media for any purpose, provided this notice is preserved along with the article's original URL.

\begin{abstract}
Background: Cervical cancer can often be prevented by screening and may be curable if identified and treated in its early stages. However, $80 \%$ of new cases occur in less-developed countries where cervical cancer screening programmes are small-scale or non-existent. This is a human tragedy of great proportion, with many of those affected being young mothers. There is some evidence that cancerous or precancerous lesions may be detected by visual inspection with acetic acid (VIA) and field studies indicate that this technique is effective, safe and acceptable to women. However, the provision of a light source for inspection of the cervix presents a major problem in less-developed countries, where candles and torches often provide the only means of illumination. Our objective was to develop a light source based on clockwork technology, that required no batteries or external power source.
\end{abstract}

Methods: We adapted the design of a commercially available clockwork torch to provide a light source for cervical inspection. The light source was then tested under laboratory conditions in a comparison with other illumination methods typically used in this application.

Results: The light source gave illuminance levels greater than those produced by any other method tested, and also had considerable advantages in terms of ease of use and safety.

Conclusion: This design is small, compact, effective and safe to use and promises a better and more affordable means of visualising the cervix. Further field trials of VIA are now required which incorporate this light source.

\section{Background}

Cervical cancer can often be prevented by screening, and may be curable if identified and treated in its early stages. However, in most less-developed countries, cervical cancer screening programmes are small-scale or non-existent. Thus there are few opportunities for the diagnosis and treatment of precancerous cervical disease. It is estimated that in excess of 470,000 new cases of cervical cancer are diagnosed each year around the world, with more than $80 \%$ occurring in less developed countries [1]. More than 233,000 women are dying from this disease each year and the morbidity is highest in those countries that are least equipped to deal with the problem. This is a human trag- 


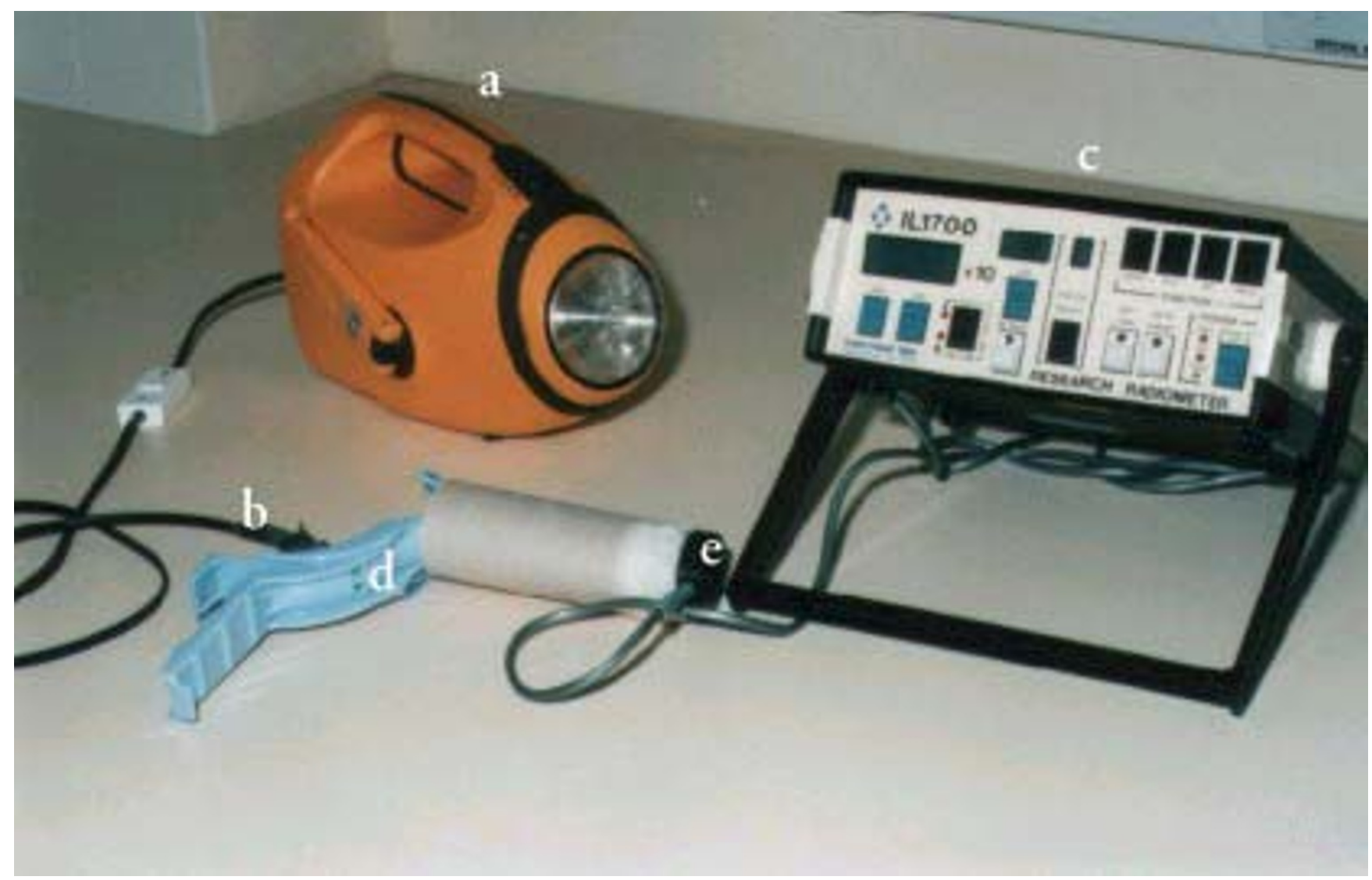

Figure I

Adapted clockwork torch a: clockwork power source b: light source c: ILI700 (light meter) d: speculum e: photoiode (light detector)

edy of great proportion, and many of those affected are young mothers.

There is some evidence that cancerous or precancerous lesions may be detected by simple inspection of the cervix [2]. The cervix is first washed with acetic acid (vinegar) solution that causes precancerous changes in the cervix to turn white. Community (village) health workers are trained to detect the abnormality with the naked eye [3]. This technique of visual inspection with acetic acid (VIA) may have potential advantages over traditional screening techniques, providing an immediate feedback of results and enabling prompt treatment [4]. Field studies indicate that this technique is both sensitive and specific, and it may provide a cheap and acceptable means of screening for cervical cancer in poor-resource locations [5]. A test and treat approach using VIA and Cryotherapy appears to be both safe and acceptable to women and providers, and has the potential to be an efficient method of cervical cancer prevention in these settings [6]. However, the provi- sion of a light source for inspection of the cervix presents a major problem in many rural communities. Many of these rural communities are without electricity, and candles and torches offer the only means of illumination (Personal Communication). In addition, portable power supplies and batteries are a desirable commodity and are rapidly diverted in other settings and applications.

Our objective was to develop a clockwork power source and light that required no batteries or external means of power. The light source needed to be small and compact enough to allow the health worker to illuminate and view the cervix, yet provide sufficient illumination to enable the identification of precancerous lesions. It was essential that the light source did not pose any hazard to either the patient or the health worker and that it was robust, and relatively inexpensive to deploy in less-developed countries. In addition, as it clips into the speculum it is likely to be contaminated by vaginal discharge and so needed to be waterproof to enable sterilisation (see figure 4 ). We be- 
lieve that with simple adaptations to existing technology, we have achieved our objective.

\section{Materials and Methods}

Recent developments in dynamo-powered devices have brought us the clockwork radio, and more recently the clockwork torch. We adapted the design of commercially available clockwork torch technology to provide a light source which could be used independently of any external power supply and required no batteries.

The components used to adapt the clockwork torch are widely available and the prototype added less than $\square 2$ (Sterling) to the cost of the Torch. (Figure 1).

The clockwork power source takes approximately 6 hrs to fully charge the batteries, giving approximately $21 / 2$ hours of continuous use. It can also be used directly from the clockwork spring in an emergency setting, whereby 60 turns on the handle will provide sufficient charge to operate the light source for around 3 minutes.

In order to assess the effectiveness of the light source, a comparison was made with a range of other illumination methods that may be typically used for this application: namely a $100 \mathrm{~W}$-desk lamp; a $40 \mathrm{~W}$-desk lamp; a torch $(0.5 \mathrm{~W})$; a small compact torch $(0.75 \mathrm{~W})$; and a candle with and without a metal reflector.

For the experimental set-up, consideration had to be given to both the anatomy of the vagina and the relative positions of the light source and health worker (Figure 2). A cylinder $4 \mathrm{~cm}$ in diameter and $11 \mathrm{~cm}$ long was used to mimic the anatomy of the vagina (reference man ICRP 23). A calibrated photodiode light detector with photopic filter (SED038 with Y filter) was sealed at the far end, where in effect the cervix would lie. A plastic speculum was introduced into the other end of the cylinder and illuminance measurements at the 'cervix' were made. In order to accurately reproduce clinical conditions, measurements were made using the light source whilst simultaneously viewing the detector or 'cervix'.

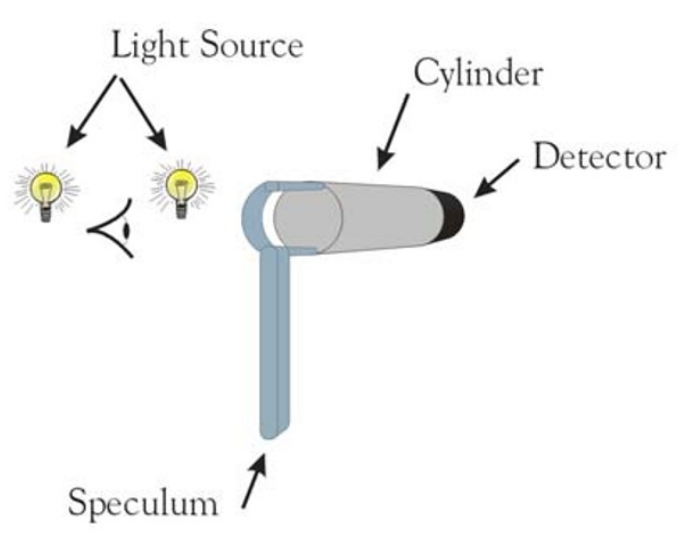

Figure 2

Experimental set-up for laboratory testing

\section{Results}

The human eye responds to a narrow band of the electromagnetic spectrum, typically $400-700 \mathrm{~nm}$ with a peak response at $555 \mathrm{~nm}$. In order to compare the different light sources it is essential that account be taken of the response of the human eye.

Illuminance (measured in lux) is the electromagnetic flux density falling on unit area, corrected for the response of the human eye. Typical flux densities encountered in daily life are shown in Table 1 and cover a large dynamic range. The human eye is able to accommodate a wide range in illuminance (Table 1).

The measured illuminance levels are shown in Figure 3. The light source gave illuminance levels greater than that of the desk lamps or torch, both of which are commonly used for cervical inspection as part of a routine gynaecological examination in the UK. Figure 3 also clearly demonstrates the poor performance of a candle in this situation, an illumination method which is commonly used in less-developed countries and which carries potential hazards both for the patient and clinician.

Table I: Typical illuminance values

\begin{tabular}{lc}
\hline & Illuminance (typical lux) \\
\hline Sunny Day & $\sim 100,000$ \\
Office Lighting & $\sim 1000$ \\
Full Moon & $\sim 0.1$ \\
\hline
\end{tabular}




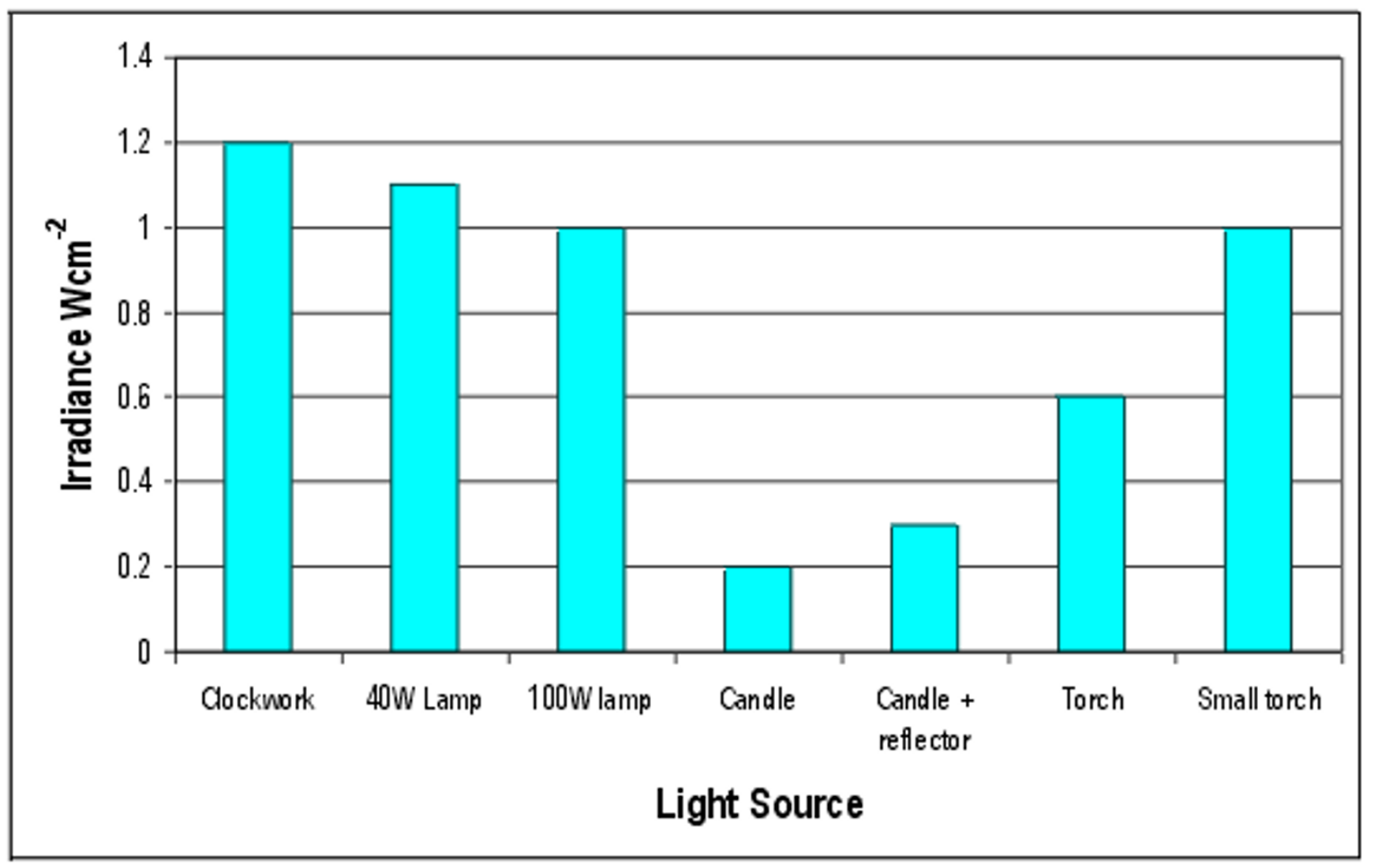

Figure 3

Measured illuminance levels of light sources

By comparing Table 1 with Figure 3, we can see that the light levels achieved at the cervix when using the light source are broadly comparable to normal office lighting.

\section{Discussion}

Cervical cancer is the third most common cancer in the world. Screening programmes aim to detect cervical cancer in its early stages and make successful treatment more likely, with the possibility of reducing the incidence and mortality. In countries where regular cervical cancer screening is available, death rates have been reduced. However, cervical cancer remains the leading cause of death from cancer among women in less developed countries, where cervical cancer screening programmes are non-existent or fragmented at best [1].

Cervical cancer screening is a complex process. Less developed countries often face economic, social and cultural constraints which prevent the implementation of organised cervical cytology screening. A recent analysis of cervical cancer screening strategies for low-resource settings found VIA to be cost-effective (\$39 per year of life saved) and when coupled with immediate treatment it reduced the incidence of cervical cancer by 26\% [7]. However, compared to cytology, VIA is less specific with low positive predictive value for high-grade disease [2]. In their report from Zimbabwe, The University of Zimbabwe/ JHPIEGO Cervical Cancer Project suggested that higher test quality for VIA could be achieved with better lighting, standardised training and better service delivery conditions [3].

The light source was the best amongst the illumination methods tested. Its illuminance was greater than that of the torch, which is still commonly used for gynaecological examination even in UK hospitals. It is not simply the power output of the light source but also how compact it is that determines the measured illuminance at the cervix. The $100 \mathrm{~W}$ and $40 \mathrm{~W}$ lamps are certainly the brightest sources used but they are large, unwieldy and must be placed behind the observer. The light source has the bulb detached from the power source, so that its size is only 


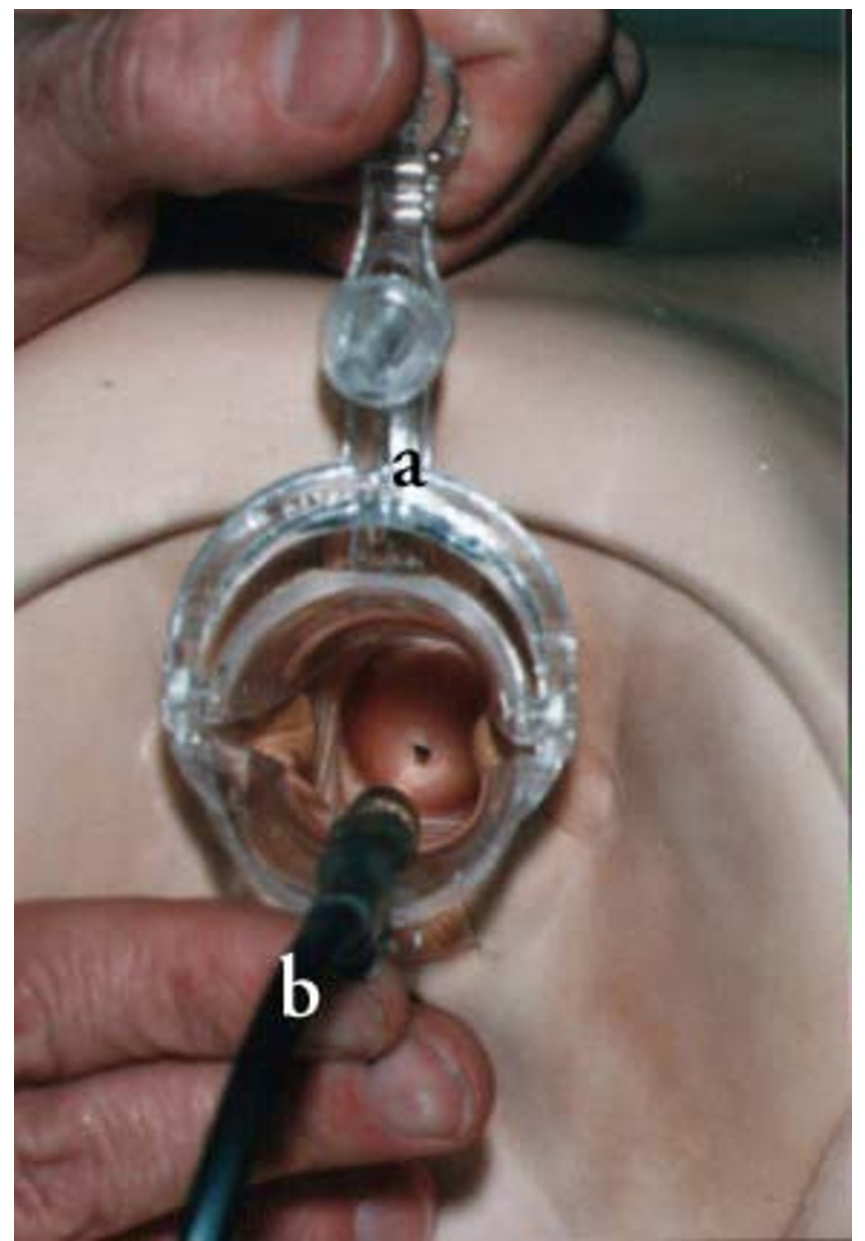

Figure 4

Clockwork light source speculum in use (simulation model) a. speculum b. light source

that of the clip and bulb. Hence it does not impede the view of the health worker. In addition the speculum clip means that the light source does not need to be held, leaving the health worker's hands free (Figure 4).

\section{Conclusion}

This design promises a better and more affordable means of visualising the cervix, and further field trials of VIA are required which incorporate this light source.

\section{List of Abbreviations}

VIA visual inspection (of the cervix) with acetic acid

\section{Competing interests}

None declared.

\section{Authors' Contributions}

This project was instigated by RJ, who directed it through to completion and wrote the first draft of this paper but died before it could be submitted for publication. Co-authors are responsible for the final form of this manuscript. All authors contributed to the development of a working prototype. Laboratory testing of the light source was undertaken by $\mathrm{BB}$ and $\mathrm{CK}$.

\section{Acknowledgements}

This paper is dedicated to Richard Johanson who died prior to publication. We are grateful to the Rotary Club for their support and encouragement. Linda Lucking prepared the manuscript.

\section{References}

I. Parkin DM, Whelam SL, Ferlay J, Raymond L and Young J Cancer incidence in five continents. IARC Scientific Publication No. 143, Lyon 1997,

2. Kitchner $\mathrm{HC}$ and Symonds $P$ Detection of cervical intraepithelial neoplasia in developing countries (Commentary). Lancet 1999, 353:856-857

3. University of Zimbabwe/JHPIEGO Cervical Cancer Project Visual inspection with acetic acid for cervical-cancer screening: test qualities in a primary-care setting. Lancet 1999, 353:869-873

4. Cervical cancer control in developing countries: memorandum from a WHO meeting. Bull World Health Organ 1996, 74:345-35।

5. Sankaranarayanan R, Wesley R, Somanathan T, Dhakad N, Shyamalakumary B, Amma NS, Parkin DM and Nair MK Visual inspection of the uterine cervix after the application of acetic acid in the detection of cervical carcinoma and its precursors. Cancer 1998, 83:2150-2156

6. Limpaphayom K, Lumbiganon P, Gaffikin L, Worakamin S, Srisupundit $S$, Ringers $P$ and Blumental $P$ Safety and acceptability of visual inspection using acetic acid (VIA) and cryotherapy for cervical cancer prevention in ROI-ET Province, Thailand. Annual Scientific Meeting of the RANZCOG, Melbourne, Australia, November 200I, Book of Abstracts 41

7. Goldie SJ, Kuhn L, Denny L, Pollack A and Wright TC Policy analysis of cervical cancer screening strategies in low-resource settings: clinical benefits and cost-effectiveness. JAMA 200I, 285(24):3107-3II5

\section{Pre-publication history}

The pre-publication history for this paper can be accessed here:

http://www.biomedcentral.com/1472-6874/2/12/prepub

Publish with Biomed Central and every scientist can read your work free of charge

"BioMed Central will be the most significant development for disseminating the results of biomedical research in our lifetime. "

Sir Paul Nurse, Cancer Research UK

Your research papers will be:

- available free of charge to the entire biomedical community

- peer reviewed and published immediately upon acceptance

- cited in PubMed and archived on PubMed Central

- yours - you keep the copyright
BiolMedcentral 